\title{
Mechanical and Physical Dynamic Effects under the Low Temperature Ductile Shear Failure of Amorphous Alloys
}

\author{
V. Bengus and V. Ocelik* \\ B. Verkin Institute for Low Temperature Physics \& Engineering of Ukraine Academy of Sciences, Lenin's \\ Avenue, 47 Kharkov 164, 310164, Ukraine \\ *Institute of Experimental Physics, Academy of Sciences of Slovakia, Watsonova 47, 04353 Kosice, \\ Slovakia
}

\begin{abstract}
It is a short review of dynamic phenomena accompanying the low temperature ductile shear failure of amorphous alloys experimentally observed in 90's. Physical mechanisms of these phenomena are discussed.

Resume. C'est une bref revision des phenomenes dynamiques accompagnant la rupture duclile par cisaillement des alliages metalliques amorphes a basse temperature, observes experimentalement dans les annees 90 . Des explications physiques de ces phenomenes sont proposees.
\end{abstract}

\section{INTRODUCTION}

The dynamic effects, arising in solids under high-speed loading, are observed both at formation and propagating of localized plastic shear bands, and at formation and spreading of cracks during the failure. These dynamic effects include local adiabatic heating-up in the volume of a localized shear band or at the front of the opening crack, emitting of elastic waves by the front of an advancing crack, branching of a main crack and other phenomena $[1,2]$. They are observed only at very high rates of localized plastic shear (adiabatic heating-up) and at very high velocities of a cracks motion, close to the sound velocity.

Dynamic effects are the most prominent at the low-temperature $\left(T<0.6 T_{g}\right.$ where $T_{g}$ is the glass transition temperature) ductile shear failure of amorphous metallic alloys, arising under quasistatic loading. The high strain-rate plastic shear under quasistatic loading arises owing to the unstable character of propagating of plastic shear in amorphous alloys (in view of absence of a work-hardening in them), in view of the large value of the critical shear stress for catastrophic plastic shear (and of the low temperature failure stress) of amorphous alloys, close to the theoretical strength, and also in view of their high local plasticity $[3,4]$. The catastrophic plastic shear in amorphous alloys precedes (or accompanies) the low temperature ductile shear failure, therefore, in these materials dynamic effects are observed, peculiar both to localized plastic shear and to the high-velocity propagation of the crack.

This article represents a brief review of the phenomena observed in experimental studies of the process of the low temperature ductile shear failure of amorphous metallic alloys, carried out in 90's [4$10]$.

\section{OBSERVED DYNAMIC EFFECTS}

As dynamic effects we consider the phenomena, that are observed at high strain-rate plastic shear and failure, and caused by high velocity of these processes, close to the sound velocity.

To these effects we classify phenomena as:

- branching of the main crack,

- repeated alteration of the shear crack plane orientation between the two conjugate " 45 -degree" orientations

- occurrence of a plastic corrugation,

- local deformation adiabatic heating-up

- local dynamic superplasticity of protruding "veins" on the ductile shear failure surfaces

- local dynamic melting during rupture of the ductile shear failure surfaces 


\subsection{Branching of the main crack}

Branching of the main crack was observed by the high-speed cinematography of the main crack propagation in "metal-metalloid" amorphous alloys ribbons during the low temperature ductile shear failure under a quasistatic uniaxial tension at the room temperature $[6,8]$. The motion of the main crack front was studied by means of a high-speed film camera (SFR-2M) with a frame frequency of $2 \cdot 10^{6} \mathrm{~s}^{-1}$. The rupture of samples took place along planes inclined at 45 degrees to the plane of ribbon. Non-uniform motion of the main shear crack front was observed and the maximum instantaneous velocity was nearly $2,5 \cdot 10^{3} \mathrm{~m} / \mathrm{s}$

This maximum velocity is very close to the $0.9 \cdot c_{t} \cong 2.2 \cdot 10^{3} \mathrm{~m} / \mathrm{s}$, predicted by continuum fracture mechanics as limiting value of the crack velocity where $c_{t}$ is the velocity of transverse elastic waves. Therefore one can conclude that the relativistic regime of the shear crack front is realized under the low temperature ductile shear failure of amorphous alloys ribbons.

The crack branching was observed at velocities close to limiting values as predicted by the theory $[2,11]$. Angles of branching close to 30 degrees predominate as the theory [11] predicts. At the moments of the start of branching the crack velocity decreases and then increases again, i. e. a pulsating motion of the crack is observed with the average velocity close to 0.5 of the maximum value [8].

\subsection{Repeated alteration of the shear crack plane orientation between the two conjugate "45-degree" orientations}

The described crack branching is a macroscopic phenomenon accompanying the unstable motion of a cracks as it observed in a variety of materials [2]. But in amorphous alloys ribbons also a microscopic manifestation of the shear crack instability is observed: changing of the shear crack plane from one the maximum shear stress plane to another one, that is conjugated to the first one, owing to the interaction of the processes of plastic shear and rupture along the spreading shear crack surface. Failure surfaces look faceted and such phenomenon is accompanied by a deceleration of the shear crack front [8].

It is evident that the time resolution of our camera was insufficient for observing the corresponding step-like process. Its existence was established due to the scanning electron microscope (TESLA BS300) observations of the crack surfaces after the failure and correlating them to measured values of the crack front velocities $V$ at different intervals of time. Typical "faceted" failure surface is shown in Figure la

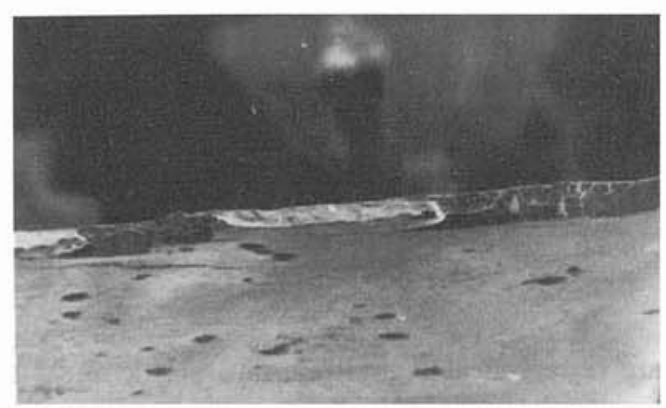

a)

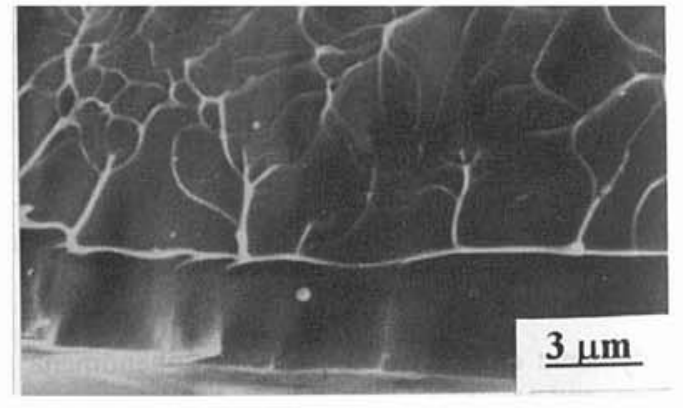

b)

Figure 1: a) "Faceted" shear failure surface of $\mathrm{Pd}_{84} 5 \mathrm{Si}_{15}$ s amorphous alloy ribbon. b) A single facet of the faceted surface of shear failure.

A part of single "facet" is shown in Figure $1 \mathrm{~b}$, where the smooth shear zone and the zone of the rupture with its "vein" morphology are clearly seen. The length of facets are log-normal distributed [7]. From the average crack velocity $\left(\sim 10^{3} \mathrm{~m} / \mathrm{s}\right)$, the average facet length $(\sim 100 \mu \mathrm{m})$ and the shear displacement 
$(\sim 10 \mu \mathrm{m})$ one can estimate the velocity of shear displacement to be $\sim 100 \mathrm{~m} / \mathrm{s}$.

Two main factors seemed to be important for the formation of the "faceted" surface. One of them is the presence of local internal stresses [12] and the other is local bending at the front of the shear crack that violates the symmetry of the ribbon stress state under uniaxial tension. This last reason for the alteration of the shear crack orientation is physically similar to the stimulation of accommodating conjugate shear bands under plane strain in crystalline solids [13]

\subsection{Plastic corrugating of amorphous alloys ribbons after dynamic failure}

It is usually seen visually that plastic corrugation appears on the gauge part of the ribbon sample (near the massive grips) after the low temperature ductile shear failure [8]. This corrugation looks as a sequence of the wave-like macroscopic folds which are most developed near the grips. These folds of corrugation are formed by aggregates of localized shear bands that are easily observed even by optical microscopy [8] that evidences the high local plasticity of amorphous alloys ribbons. The origin of the described corrugation is easily understood considering that the crack velocity is close to the sound velocity. Thus elastic waves must be formed in the ribbon during the time $t_{f}$ of crack propagation from one edge of the ribbon sample to the other. These waves will propagate from the point of the crack initiation to the grips of the sample. Let this propagation continue during time $t_{l}$. Then the condition for the origin of the elastic unloading wave is

$$
t_{f} / t_{l}<1
$$

Considering velocities of both crack propagation $\left(\sim 0.9 c_{t}\right)$ and longitudinal sound $\left(\sim 1.5 c_{t}\right)$ and dimensions of studied ribbon samples $(10 \times 25 \mathrm{~mm})$ one obtains: $t_{f} \sim 10 / 0.9 c_{t} ; t_{l} \sim 25 / 1.5 c_{t} ; t_{f} / t_{l} \sim 0.65<1$ [8]. Hence, elastic waves are really emitted from the region of the shear failure of the amorphous ribbon.

Theoretical analysis [14] has shown that in similar conditions one of the waves is a longitudinal unloading wave (compression) while the others are flexural strain waves. These last are caused by the local bending moment arising in the region of the failure beginning. Apparently, simultaneous action of the compressive longitudinal wave reflected from the massive grip and the emitted flexural strain waves cause plastic corrugation of amorphous alloys ribbons

\subsection{Local deformation adiabatic heating-up}

Dissipation of the work of plastic deformation in the localized shear region results in local heating of this region. This heating is higher when the specific power of plastic deformation is greater due to its higher localization or higher strain-rate $[1,15,16]$. Direct measurements of the local temperature in polycrystalline metals showed that local heating achieves there several hundreds of degree in the bands of $200 \mu \mathrm{m}$ width $[1,15]$. In the Ti-8wt.\%Mn indirect indications even of melting was observed on the ductile shear failure surfaces [17].

An extreme deformation heating was supposed [4, 5]under the catastrophic plastic shear in amorphous alloys due to: the very small shear band width $d(5-20 \mathrm{~nm}[18,19])$, very short duration $\Delta t$ of the catastrophic shear (several $\mu \mathrm{s}$ ), large the local shear deformation $\Delta \varepsilon(-100)$ and the failure stress $\sigma_{f}$ of the order of the theoretical strength $G / 30$ (where $G$ is the shear modulus). Estimation of the specific work of plastic deformation $W_{p}$ in the unit volume of the catastrophic shear band according to

$$
W_{p}=\int_{0}^{\Delta t} \sigma(t) \cdot \varepsilon_{p}(t) d t=\sigma^{*} \cdot \Delta \varepsilon
$$

where $\sigma^{*}$ is the average stress acting during the time $\Delta t$ at shear rate $\varepsilon_{p}$. At $\sigma^{*} \sim \sigma_{f} \sim 2 \mathrm{GPa}$ [8] one obtains $W_{1} \sim 100 \mathrm{GJ} / \mathrm{m}^{3}$ that is enough even for melting in the catastrophic shear band if the adiabaticity condition is fulfilled; i.e 


$$
\sqrt{\Delta t \cdot D} \sim d
$$

where the thermal diffusion coefficient $D$ is of the order of $10^{-7} \mathrm{~m}^{2} \mathrm{~s}^{-1}$ (at room temperature). It is easy to estimate that for a single facet of the failure surface, when $\Delta t \sim 0.01 \mu \mathrm{s}$, the shear is adiabatic as was supposed by Leamy et al [20]. Therefore, local deformation heating during the catastrophic shear must be high enough even for local melting.

To check the hypothesis of the "up to melting heating" we have measured integral heating $\Delta T_{\imath}$ of some amorphous alloy ribbons owing to the catastrophic shear and subsequent rupture under uniaxial tension at $0.5 \mathrm{~K}$ inside the cryostat filled with liquid ${ }^{3} \mathrm{He}$ [5]. The $\Delta T_{1}$ values were measured by means of a semiconductor resistance thermometer placed near the sample surface. $\Delta T_{i}$ and $\sigma_{f}$ were $0.15 \mathrm{~K}$ and $2.3 \mathrm{GPa}$ respectively for $\mathrm{Fe}_{40} \mathrm{Ni}_{40} \mathrm{P}_{14} \mathrm{~B}_{6}$ and $0.04 \mathrm{~K}$ and $1.4 \mathrm{GPa}$ for $\mathrm{Pd}_{84.5} \mathrm{Si}_{15.5}$. Local temperature increase $\Delta T_{l}$ in the catastrophic shear region was estimated from $\Delta T_{l}$ using the heat balance equation [5] and the evident relation:

$$
\Delta T_{l} \gg \Delta T_{i} \cdot L / d
$$

For the sample length $L$ of $10 \mathrm{~mm}$ and $\sqrt{\Delta t \cdot D}$ equal to $50 \mathrm{~nm}$ we obtain $\Delta T_{i} \gg 10^{3} \mathrm{~K}$ that exceeds $T_{m} \sim 1800 \mathrm{~K}$. Hence our experimental measurements confirmed the hypothesis of deformation heating "up to the melting temperature" under the low-temperature ductile shear failure (including the catastrophic shear and rupture).

Under-estimates of the local deformation heating published in $70^{\prime} \mathrm{s}[21,22]$ were caused by the absence of experimental data on the unstable character of localized plastic shear in amorphous alloys. It is well known now that the local strain-rate in shear bands exceeds the quasi-static extension rate by many orders of magnitude [4].

\subsection{Local dynamic superplasticity of protruding "veins" on the ductile shear failure surfaces}

Hot and soft but not liquid state of a material inside the catastrophic shear band before rupture is evidenced by grooves on the shear surfaces that were formed by moving macroscopic inclusions along the shear surface [4] of amorphous alloy ribbons. Therefore the notion about a thin "liquid-like" layer existing along the surface of catastrophic shear [23] seems better to substitute by the notion of a hot solid layer in the superplastic state with a small but "non-zero plastic resistance" [23]. The more that experimentally it is possibie to distinguish different superplastic state of this layer in amorphous alloys of different chemical compositions by observation of protruding "veins" on the shear failure surfaces.

We have estimated the plastic deformation $\varepsilon$ of protruding "veins" in different alloys by fractographic analysis and correlated its magnitude with vitrification intervals $\Delta T$ of respective alloys known from the literature [10]. It turned out that the larger $\Delta T$ the larger $\varepsilon$. In the series of amorphous alloys: $\mathrm{Cu}_{50} \mathrm{Zr}_{35} \mathrm{Ti}_{8} \mathrm{Hf}_{5} \mathrm{Ni}_{2}, \mathrm{Pd}_{84.5} \mathrm{Si}_{15.5}, \mathrm{Fe}_{84} \mathrm{~B}_{16}$ and $\mathrm{Fe}_{80} \mathrm{~B}_{20}-\Delta T$ decreases from higher than $10^{2} \mathrm{~K}$ to smaller than $10 \mathrm{~K}$. Respectively the $\varepsilon$ value decreases from higher than $10^{3} \%$ (long oblique "veins" in Figure 2 a) to zero (complete absence of protruding "veins" at the failure surfaces of $\mathrm{Fe}_{80} \mathrm{~B}_{20}$ ).

It is known that a magnitude of superplastic deformation increases with increasing of the heating rate to the deformation temperature [24]. May be observed large local dynamic superplasticity during the rupture of the shear failure surfaces arises due to the very high local rate of deformation heating (estimation of this rate from [8] gives $10^{8} \mathrm{~K} / \mathrm{s}$ ) that results in a "liquid-like" behaviour.

\subsection{Local dynamic melting during rupture of the ductile shear failure surfaces}

Fractographic observations (Figure 2 b) give almost obvious evidence of liquid phase presence at the last stage of the shear failure (during the nupture): there are a lot of spheroidal drops arising probably during 
the failure of protruding "veins". At this moment the additional heating must arise owing to complex processes of the energy redistribution in the electronic subsystem of solids[25]. Probably this additional heating is enough for local melting of already extremely heated material due to plastic deformation heating.

\subsection{Overlapping of fallen protruding "veins" on the failure surfaces of bulk metallic glasses}

Scraps of protruding "veins" fly away during the rupture of failure surfaces and fall on these surfaces. In bulk amorphous alloys (that have large intervals of vitrification) these scraps conserve for a long time their superplastic state during the failure. Therefore, they fall on the failure surfaces in the soft state and been overlapped go round one another, that is seen clearly in the Figure $2 \mathrm{c}$

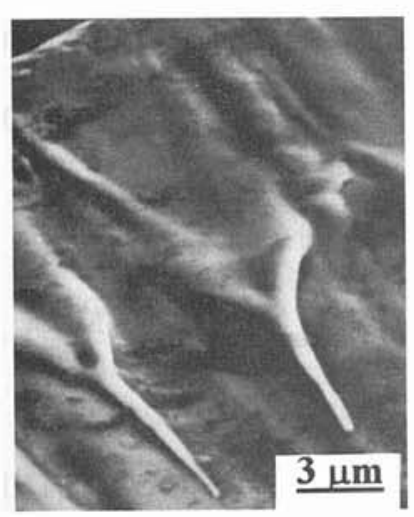

a)

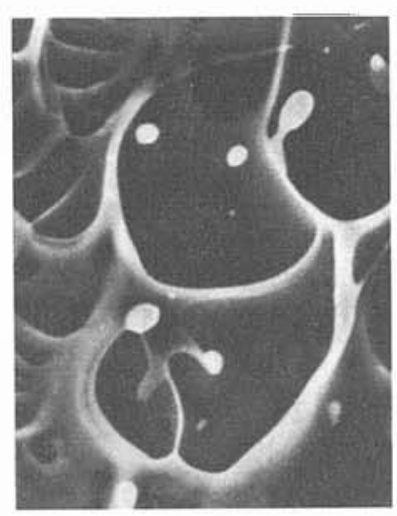

b)

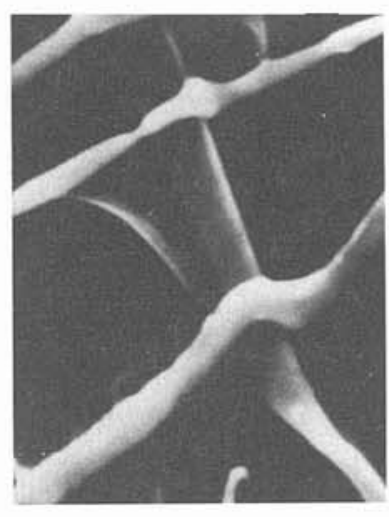

c)

Figure 2: "Vein" patterns on the ductile shear failure surfaces of the $\mathrm{Cu}_{50} \mathrm{Zr}_{35} \mathrm{Ti}_{8} \mathrm{Hf}_{5} \mathrm{Ni}_{2}$ bulk amorphous alloy deformed by uniaxial compression. a) Oblique veins elongated along the shear direction and fallen on the surface: b) Spheroidal drops; c) Fallen protruding veins go round one another.

It is some more indication of a high temperature state of "veins" on the failure surfaces.

\section{CONCLUDING REMARKS}

Existence of dynamic effects at the low-temperature ductile shear failure of amorphous metallic alloys under a quasi-static loading is connected mainly with the absolutely unstable character of the localized plastic shear in amorphous alloys. Some of these effects are typical of response of solids to high-rate straining (adiabatic heating, emitting of elastic waves) and have physically similar regularities.

\section{Acknowledgements}

We would like to acknowledge all the members of groups who have contributed to this work over the years, including especially: K. Csach, Yu. I. Golovin, V. Hajko, Jr., M. V. Makarov, J. Miskuf, A. A. Shibkov, S. E. Shumilin, E. D. Tabachnikova. Authors are grateful to Professor H. Neuhauser (Technical University of Braunschweig) for useful discussions. The research described in this publication was made possible in part by Grant \# U22200 from Joint Fund of the Government of Ckraine and International Science Foundation 


\section{References}

[1] Marchand A. and Duffy J., J. Mech. Phys. Solids 36 (1988) 251-283.

[2] Finkel V.M., Physics of Failure (Metallurgia publishers, Moscow, 1970) 376 pp.

[3] Davis L.A., "Strength, ductility and toughness", in "Metallic Glasses", N. Grant and B. Gissen Eds. (ASM, metals Park, OH, 1978) pp. 190-214.

[4] Bengus V.Z., "Some physical effects at unstable localized shear and fracture of amorphous alloys ribbons", in "Non-Linear Phenomena in Materials Science II", G. Martin and L. Kubin Eds., Solid State Phenomena 23 \& 24 (Trans Tech Publications, Zurich, 1992) pp. 347-354.

[5] Tabachnikova E.D., Shumilin S.E., Bengus V.Z., Voronova L.I. and Efimov J.V., Metallofizika 13 (4) (1991) 47-55

[6] Bengus V.Z., Golovin Yu.I, Makarov M.V., Tabachnikova E.D. and Shibkov A.A., Latvian J. Phys. \& Techn. Sciences No.5 (1991) 41-45

[7] Ocelik V., Bengus V.Z., Diko P., Hudak O., J. Mater. Sci. Lett. 6 (1987) 1333-5

[8] Bengus V.Z., Tabachnikova E.D., Shumilin S.E., Golovin Y.I., Makarov M.V., Shibkov A.A., Miskuf J., Csach K. and Ocelik V., Intern. J. Rapid Solidification 8 (1993) 21-31.

[9] Tabachnikova E.D., Bengus V.Z., Molokanov V.V., Materials Science Forum 225-227 (1996)107112 .

[10]Bengus V., Tabachnikova E., Csach K., Miskuf J. and Ocelik V., Scripta Materialia 35 (1996) $781-784$.

[11] Yoffe E.H., Phil. Mag. 42 (1951) 391-411.

[12] Kronmuller H., Fahnle M., Domann M., Grimm H., Grimm R. and Groger B., Journ. Magn. Magn. Mater. 13 (1979) 53-70

[13] Lee W. B. and Chang K. C., Scripta Met. 24 (1990) 997-1002.

[14] Miklowitz J., J. Appl. Mechanics 20 (1953) 122-134.

[15] Duffy J., J. Physique IV, Colloque C3, suppl. au J. Physique III 1 (1991) 645-652.

[16] Grady D.E., J. Physique IV, Colloque C3, suppl. au J. Physique III 1 (1991) 653-660.

[17] Makel D.D. and Wilsdorf H.G.F., Scripta. Met. 21 (1987) 1229-34.

[18] Miskuf J., Csach K., Ocelik V., Bengus V.Z. and Tabachnikova E.D., Kovove Materialy 34 (1996) 329-335.

[19] Donovan P.E. and Stobbs W.M., Acta Met. 29 (1981) 1419-36.

[20] Leamy H.Y., Chen H.S. and Wang T.T., Metall. Trans. 3 (1972) 699-708.

[21] Pampillo C.A., J. Mater. Sci. 10 (1975) 1194-1227.

[22] Argon A.S., Acta Met. 27 (1979) 47-58.

[23] Argon A.S. and Salama M., Mater. Sci. Eng. 23 (1976) 219-230.

[24] Khonik V.A. and Zelenskii V.A., Fizika Metallov i Metallovedenie 61 (1986) 602-607.

[25] Eberhart M.E., "Quantum Mechanics and Fracture" in "Advances in the Mechanics and Physics of Surfaces”, R.M. Latanision and T.E. Fisher Eds. (Harwood Acad. Publ., N.Y., 1986) 71-108. 